\title{
Iliac Osteomyelitis and Gluteal Abscess Following an Intramuscular Injection
}

\author{
Daas $S^{1,2}$, Jidi $M^{1,2}$, Slama SB ${ }^{1,3}$, Chaabane $I^{1,4^{*}}$, Souissi $M^{1,2}$ and Khorbi $A^{1,2}$ \\ ${ }^{1}$ University Tunis El Manar, Faculty of Medicine of Tunis, 1007, Tunis, Tunisia \\ ${ }^{2}$ Department of Orthopaedic Surgery, MT Maamouri Hospital, 8050 Nabeul, Tunisia \\ ${ }^{3}$ Department of Pathology, M. Slim Hospital, 2046 Sidi Daoud, Tunis, Tunisia \\ ${ }^{4}$ Department of Internal medicine, MT Maamouri Hospital, 8050 Nabeul, Tunisia
}

${ }^{*}$ Corresponding author: Chaabane Imen, Department of Internal medicine, MT Maamouri Hospital, 8050 Nabeul, Tunisia, Tel: +21655270739; E-mail: imen_chaabane@hotmail.fr

Received date: October 24, 2018; Accepted date: November 20, 2018; Published date: November 23, 2018

Citation: Daas S, Jlidi M, Slama SB, Chaabane I, Souissi M, Khorbi A (2018) Iliac Osteomyelitis and Gluteal Abscess Following an Intramuscular Injection. Arch Med Vol No:10 Iss No:6:4

Copyright: @2018 Daas S, et al. This is an open-access article distributed under the terms of the Creative Commons Attribution License, which permits unrestricted use, distribution, and reproduction in any medium, provided the original author and source are credited.

\section{Abstract}

Gluteal abscess following intramuscular injections are more common, often due to non-sterile injection techniques. We present a case of iliac osteomyelitis and gluteal abscess mimicking a tumor disease.

Keywords: Gluteal abscess; Staphylococcus aureus; Intramuscular injection

\section{Introduction}

Local infections are one of the most common infections among intramuscular (IM) injections. It can rarely result in serious infectious complications such as abscesses, osteoarticular infections which may progress to bacteraemia and generalized sepsis [1,2]. However their incidence is difficult to estimate. Staphylococcus aureus is the most common organism usually isolated in these complications $[1,3]$. We describe a case of iliac osteomyelitis and gluteal abscess due to Staphylococcus aureus following IM injection.

\section{Case Observation}

A 63-year-old female patient presented with a two months history of left hip pain with asthenia and weight loss without fever. She had no past medical history. Examination revealed a swelling in the iliac wing (Figure 1) and a hip flexion pain. Laboratory tests showed biological inflammatory syndrome. Standard X-rays were normal. Imaging studies were performed, including pelvic, abdominal and chest Computed
Tomography (CT) and pelvic Magnetic Resonance Imaging (MRI) (Figures $\mathbf{2 a}$ and $\mathbf{2 b}$ ). The $\mathrm{CT}$ and MRI examination of the pelvis demonstrated $8 \times 4 \mathrm{~cm}$ sized soft-tissue mass in the region of left gluteus muscles with a lytic lesion of the left iliac wing. A buttock tumor was suspected. The chest and abdominal CT were performed for detecting metastasis prior to surgery. The patient underwent surgery. The surgical specimen showed a yellow lobulated mass measuring $6 \mathrm{~cm}$ with areas of necrosis and purulent fluid (Figures $3 a$ and $3 \mathbf{b}$ ). A bone biopsy was performed. The bacteriological cultures revealed methicillin-sensitive Staphylococcus aureus. Histological study's piece was in favor of a left gluteal abscess. The resumption of the interrogation of the patient showed that she had a history of a Diclofenac IM injection taken on her left gluteal region 2 months ago. The patient was under antibiotic therapy based on intravenous oxacillin (12 g/day) for 4 weeks. This treatment was relayed by ciprofloxacin orally for a total duration of 2 weeks. The evolution was marked by the improvement of the symptomatology and the negativity of the biological test (Supplementary File 1).

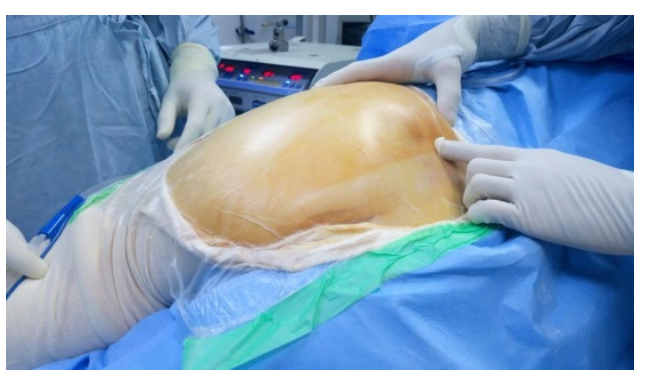

Figure 1: Posterior swelling in the iliac wing. 


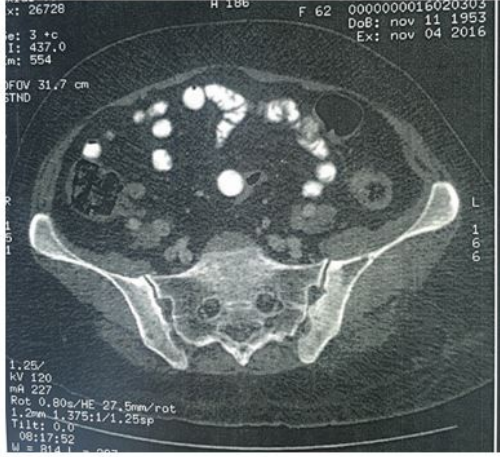

$2 \mathrm{~A}$

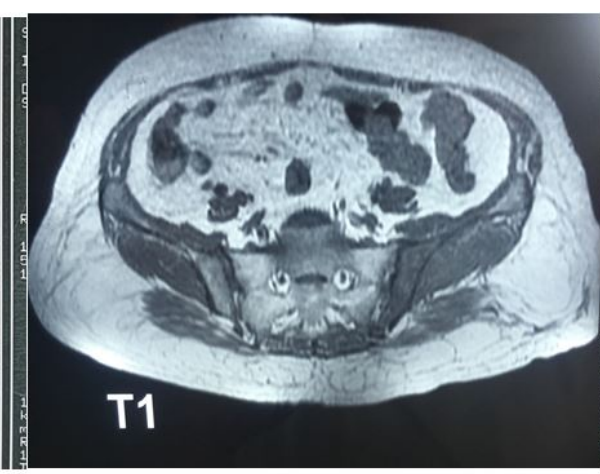

$2 B$

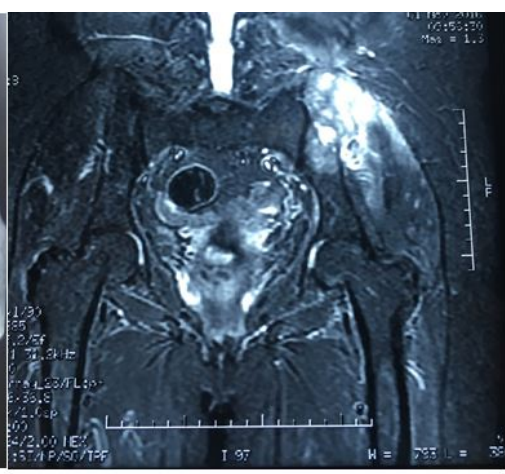

$2 \mathrm{C}$

Figure 2: (A)CT scan of pelvis shows lytic lesions of the left iliac wing and hypodense plaques infiltrating the subcutaneous fat and the gluteus medius muscle, $(B, C)$ pelvic MRI shows soft tissue masses extending into left buttock with lytic lesions of the left iliac wing.

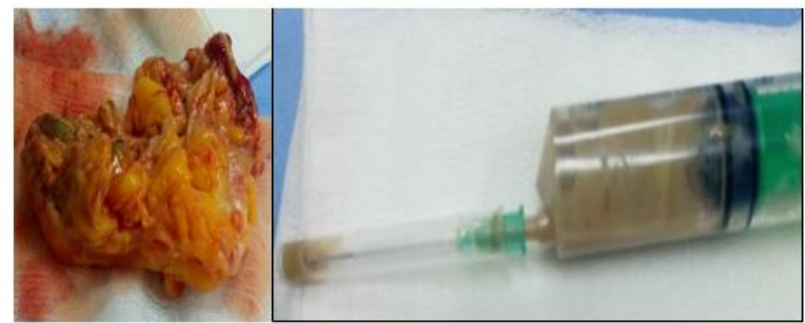

$3 \mathrm{~A}$

$3 \mathrm{~B}$

Figure 3: Intraoperative appearance showing subcutaneous tissue with purulent fetid secretion $(A, B)$.

\section{Discussions}

The administration of intramuscular injections is a common nursing intervention in clinical practice. It should be done with care to avoid complications. Today, the incidence of developing a complication from IM injections ranges from 0.4 percent to 19.3 percent of patients receiving the IM injection of a medication [4]. Gluteal abscess was the most common complication of IM injections, it has been reported by various authors $[4,5]$. While, in literature, there aren't many cases of osteoarticular infections developed after intramuscular injections.

The mechanism of the infection is probably related to direct or drug-induced tissue trauma, tissue ischemia and inoculation of bacteria. In developing countries, abscesses are secondary to injection involving unsterile techniques including the use of contaminated needles and dirty clothes. These infections are most likely to occur in immunocompromised patients, but also have been described in immuno-competent people [4-6].

Given the rarity of the condition and its relatively nondescript clinical presentation, it is almost impossible to suspect the diagnosis at first encounter. This explains the high rate of initial mis-diagnosis, and hence delayed treatment [7].
Detailed history and a careful clinical examination are essential.

CT scan are needed to confirm the diagnosis or to exclude accompanying diseases [5]. The literature does not describe the imaging characteristics of gluteal abscesses. In our case, gluteal abscesses were observed after a two months of injections in the form of Soft tissue mass.

The main treatment of gluteal abscess is surgical associated with antibiotic therapy. There is no consensus regarding the management of these infections. In summary, gluteal abscess disease is still common despite improvements in antiseptic techniques. It poses a diagnostic challenge for the clinician and the radiologist because of its nonspecific and misleading symptoms. Furthermore, we want to underline the importance of correct anamnesis to make quickly the right diagnosis and provide the right treatment.

\section{References}

1. Sambandam SN, Rohinikumar GJ, Gul A, Mounasamy V (2016) Intramuscular injection abscess due to VRSA: A new health care challenge. Arch Bone J 4: 277-281.

2. Velissaris D, Matzaroglou C, Kalogeropoulou C, Karamouzos V, Filos K, et al. (2009) Sepsis requiring intensive care following intramuscular injections: Two case reports. Cases J 2: 7365.

3. Ozucelik DN, Yucel N, Coskun S, Cobanoglu M, Kunt MM (2007) Gluteal abscess following intramuscular injection of dissolved biperiden tablets. Int J Clin Pract 61: 1417-1418.

4. Mcivor A, Paluzzi M, Meguid MM (1991) Intramuscular Injection Abscess-Past Lessons Relearned. N Engl J Med 324: 1897-1898.

5. Peungjesada S, Gupta P, Rice GD, Ghole V, Ketkar M (2009) Bilateral sterile gluteal abscesses following intramuscular injection of Penicillin: CT appearance. Internet J Radiol 12: 11947.

6. Kershaw CJ, Bulstrode CJ (1988) Gas gangrene in a diabetic after intramuscular injection. Postgrad Med J 64: 812-813.

7. King JJ, Friedman JR, Iwenofu OH, Ogilvie CM (2008) Buttock Mass in a 46-year-old Woman. Clin Orthop 466: 2023-2028. 